\title{
Physical activity and supervised exercise among hypertensives and normotensives: status and barriers
}

\author{
Dulce Esteves ${ }^{1} \cdot$ Paulo Duarte $^{2}$ (D) Paulo Pinheiro ${ }^{2} \cdot$ Rui Brás $^{1} \cdot$ Ricardo Gouveia Rodrigues $^{2} \cdot$ Ana Gouveia $^{3}$. \\ Kelly O'Hara ${ }^{1}$
}

Received: 18 July 2019 / Accepted: 14 November 2019

(c) Springer-Verlag Italia S.r.l., part of Springer Nature 2019

\begin{abstract}
Purpose Physical activity (PA) is considered central to hypertension prevention and management. The main purpose of this article is to compare supervised exercise (SE) patterns among hypertensive and normotensive Portuguese adults.

Methods A total of 966 participants aged between 15 and 90 years old (mean 41.9; SD 19.5) were surveyed face-to-face in public places across Portugal. Participants were considered hypertensives $(n=144)$ if they have systolic and diastolic blood pressure higher than 160 and $90 \mathrm{mmHg}$ or report taking antihypertensive medication. PA was assessed using the International Physical Activity Questionnaire (IPAQ). Descriptive statistics, Chi-square test for associations and $t$ test for independent samples were used to analyze data.

Results Hypertensive individuals show a higher prevalence of sedentary lifestyle than normotensive (31\% vs $20 \%$ ). About $40 \%$ of hypertensive patients have a high level of physical activity. Several significant differences were found between hypertensives and normotensives regarding the causes for non-participation, information sources and motivation to participate. For infrastructures, only the quality of the equipment $(p=0.032)$, innovative activities $(p=0.027)$, and the opportunity to socialize $(p=0.000)$ are capable of differentiating the two groups.

Conclusions This study shows the prevalence of sedentary behavior among the hypertensive population. Hypertensives and normotensive behavior reveal different patterns on the barriers, sources of information, and perception regarding the structures. Service providers seem incapable to make hypertensives aware of the risks associated with PA and the benefits associated with SE. More information is needed to make hypertensives aware of the benefits of SE programs.
\end{abstract}

Keywords Hypertension · Health · Physical activity · Supervised exercise · Program attendance promotion · Promotion · Information sources $\cdot$ Sports health

Paulo Duarte

pduarte@ubi.pt

Dulce Esteves

desteves@ubi.pt

Paulo Pinheiro

pgp@ubi.pt

Rui Brás

rmmb@ubi.pt

Ricardo Gouveia Rodrigues

rjagr@ubi.pt

Ana Gouveia

agouveia@ubi.pt

Kelly O'Hara

ohara@ubi.pt
1 Universidade da Beira Interior, Research Center in Sports Sciences, Health Sciences and Human Development (CIDESD), Rua Marquês d'Ávila e Bolama, 6201-001 Covilhã, Portugal

2 Research Unit in Business Sciences (NECE), Universidade da Beira Interior, Rua Marquês d'Ávila e Bolama, 6201-001 Covilhã, Portugal

3 Instituto de Biofísica e Engenharia Biomédica, Faculdade de Ciências, Universidade da Beira Interior, Universidade de Lisboa, Rua Marquês d'Ávila e Bolama, 6201-001 Covilhã, Portugal 


\section{Introduction}

Worldwide prevalence of hypertension exceeds 1.3 billion people [1] and this number is anticipated to reach 1.56 billion by 2025 [2]. Hypertension is a significant risk factor for stroke, acute myocardial infarction, heart failure, and sudden death [3]. Its high prevalence implies significant medical costs: the global direct medical costs of hypertension are estimated at $\$ 370$ billion per year [4]. Therefore, hypertension prevention strategies are important for public health $[5,6]$. Lowering blood pressure can be achieved using a pharmacologic strategy or by promoting lifestyle changes such as weight loss, moderation of alcohol intake, reduced saturated fat and salt intake, and finally, increased physical activity (PA) [5-8].

Physical activity is considered a cornerstone in the prevention and management of hypertension [8,9]. Epidemiological studies indicate that high levels of PA are associated with lower blood pressure, and meta-analyses of randomized controlled trials have shown that aerobic endurance training is able to control hypertension [6, 10-12]. Among the major responses to PA is post-exercise hypotension that promotes chronic adaptations and acute responses within the cardiovascular system. These changes have relevant clinical implications for hypertensive subjects indicating that post-exercise hypotension can act as an important nonpharmacological agent for hypertensives [7]. Besides exercise hypotension, PA has been shown to increase the capillary-to-fiber ratio in humans [13] and improve vascular function by improving the balance between vasodilator and vasoconstrictor systems [14]. Due to the evidence, both the American Heart Association and American College of Cardiology [15] and the Sixth Joint Task Force of the European Society of Cardiology [16] developed guidelines for lifestyle management and changes in persons diagnosed with hypertension in what refers to PA. These recommendations converge to $150 \mathrm{~min}$ of weekly PA or dynamic aerobic endurance training for at least 30 min daily, preferably supplemented with dynamic resistance exercise [15]. In spite of these references, the effects of exercise training vary with exercise characteristics, such as exercise modalities (endurance training or resistance exercise), intensity/workload, program length, session duration, frequency, among others [11]. According to the authors, exercise efficacy in reducing blood pressure is dependent on how adequate the exercise is to each individual. More important than being autonomously active, it is central to participate in supervised exercise (SE) programs, specifically designed to attend individual needs and being oriented by a professional, certified instructor.

Regarding the benefits of SE compared with selfmanaged PA, studies [17] report that SE promotes arteriogenesis (potentially lowering blood pressure) more efficiently than non-supervised exercise. Other studies [18] consider that SE as a highly effective treatment that should be recommended as first-line therapy when compared to home-based PA. When recommending the self-managed walk to increase the PA level among hypertensives, little attention has been given to the underlying theoretical basis of the program being tested, namely the type of walking, how it relates to the individual response, and how adequate it is to that particular condition [19]. The lack of evidencebased theoretical support may impair results in blood pressure management.

Besides other benefits, SE provides effective exercise risk management. People with blood pressure $>180 / 105 \mathrm{mmHg}$ should not begin the regular physical activity until after pharmacological treatment has been initiated and recommend caution in the case of high-intensity dynamic training or strength training with very heavy weights [3]. SE should provide blood pressure control during exercise and prescribed intensity based on individual response to minimize health risks.

Based on these findings, it seems clear that exercise is an important adjuvant therapy for hypertension prevention and management, but its effectiveness depends on how well it is performed, being SE more effective. In spite of the evidence, the literature refers that people with hypertension are often unwilling to participate in exercise programs due to specific barriers and because not enough information is available to persuade patients and providers to take concrete actions and modify the sedentary behavior [18]. These conclusions stress the need for better education and more information regarding the benefits of SE programs specially tailored for people with hypertension.

The American College of Cardiology/American Heart Association Task Force [15] considers that future research needs to determine strategies for effectively implementing PA recommendations. Establishing strategies that promote the attendance to SE specifically designed to hypertensive population should consider local characteristics, and the interventions should be based on deep knowledge about the target population to target both the promotional information and the SE to the perceived needs and objectives. Accordingly, it is important to evaluate the differences between hypertensive individuals and the rest of the population regarding the participation in SE programs to evaluate if there are differences that demand the elaboration/ revision of PA programs to foster attendance.

The main objective of this research is to compare SE patterns among hypertensive and normotensive Portuguese adults. The specific objectives are to compare: (i) PA level; (ii) attendance to SE programs; (iii) PA information sources; (iv) intention to participate in different types 
of pre-defined programs and (v) the perceived importance of the structure that hosts the exercise program.

The findings are valuable to support the development of strategies that lead hypertensives to become more active by engaging in supervised intense PA activities. Achieving this outcome is important for hypertensives since the adherence to a personalized exercise and supervised by accredited professionals can simultaneously increase the benefits of PA in blood pressure control, diabetes management, and physical health. The findings are also important for promoters of PA programs such as gyms, health clubs, among others, as it can help to attract hypertensives for their businesses.

\section{Methods}

This investigation reports a cross-sectional population-based study in Portugal. A total of 966 participants aged between 15 and 90 years old (mean 41.9; SD 19.5) were surveyed, using a structured questionnaire. Participants were recruited in public places (such as city centers, public gardens and parks, commercial areas, hospitals, and medical centers), across Portugal (North, Center, South, and Islands) in large, medium and small cities, and in rural villages. After the presentation of researchers' affiliation, investigation goals and guaranty of confidentiality, participants were completely free to decide if they want to participate.

For the purpose of the current study, participants were considered to have Hypertension $(n=144)$ if they have systolic and diastolic blood pressure higher than 160 and $90 \mathrm{mmHg}$, respectively, measured at least twice by the general practitioner before questionnaire, or those already receiving antihypertensive treatment (self-reported) [20].

PA was assessed using the Portuguese validated short version [21] of the International Physical Activity Questionnaire (IPAQ) [22] which estimates PA across a comprehensive set of factors to yield a score in metabolic equivalents (METS)-minutes.

Attendance to SE programs was evaluated using a threepoint Likert scale (rarely—sometimes—often), across three kinds of PA program providers: gym/health clubs; swimming pools and other clubs/sports facilities. Measures for PA barriers were adapted from Thomas, Alder, and Leese [23] and evaluated with a five-point Likert scale. PA information sources were evaluated using the scales by Pinheiro, Esteves, and Brás [24].

To ensure content and face validity, all items were reviewed by an expert panel of professors and researchers not involved in the study. The board consisted of two sports scientists (with research experience), one expert researcher on market research and survey development and one researcher expert on knowledge management. The pre-tested by fieldwork supervisors with a sample of 25 individuals to ensure clarity and completion time. Final data were collected by nine researchers (post-graduate students) after attending a $10 \mathrm{~h}$ training course. Statistical Package for Social Sciences (SPSS) version 25 was used to obtain the descriptive statistics and perform the Chi-square test for associations, and $t$ tests for independent samples were used to analyze data. The $0.05 p$ value threshold was applied to gage statistical significance.

The study protocol conformed to the Declaration of Helsinki and was conducted with the University of Beira Interior Scientific Committee of the Ph.D. in Sports Science approval.

\section{Results}

\section{Supervised vs. self-selected PA among hypertensive and non-hypertensive}

Regarding PA level was assessed through IPAQ and no statistically significant differences were found between the two groups. The PA level for hypertensive is $31.3 \%$ low; $28.5 \%$ moderate, and $40.3 \%$ high, whereas for normotensive is $20.4 \%$ low; $29.5 \%$ moderate, and $48.5 \%$ high. Nevertheless, among hypertensives, there is a higher prevalence of lower and higher PA level, suggesting the existence of two main types of PA behaviors: a group of more active individuals who are already engaged in PA routines and a more sedentary one (31\%) that does not conform with PA recommendations. Although $69 \%$ of hypertensives report moderate or high physical activity, it is mostly unsupervised exercise since they do not visit sports facilities as shown in Table 1. The results point to that both hypertensive and normotensive opt for self-selected physical activity over SE. Hypertensives present a lower participation level in gym/ health clubs and on sports clubs than normotensives. No

Table 1 Attendance of sport facilities

\begin{tabular}{|c|c|c|c|c|}
\hline & Rarely & Sometimes & Often & $\chi^{2}$ \\
\hline \multicolumn{5}{|c|}{ Do you attend a swimming pool? } \\
\hline Hypertensive & $125(86.8 \%)$ & $8(5.6 \%)$ & $11(7.6 \%)$ & \multirow[t]{2}{*}{2.648} \\
\hline Normotensive & $668(81.2 \%)$ & $67(8.1 \%)$ & $87(10.7 \%)$ & \\
\hline \multicolumn{5}{|c|}{ Do you attend any gym/health club? } \\
\hline Hypertensive & $126(87.5 \%)$ & $8(5.6 \%)$ & $10(6.9 \%)$ & \multirow[t]{2}{*}{7.929} \\
\hline Normotensive & $640(77.9 \%)$ & $55(6.7 \%)$ & $127(15.5 \%)$ & \\
\hline \multicolumn{5}{|c|}{$\begin{array}{l}\text { Do you attend any other club/sports facilities to do some physical } \\
\text { activity? }\end{array}$} \\
\hline Hypertensive & $128(88.9 \%)$ & $3(2.1 \%)$ & $13(9.0 \%)$ & \multirow[t]{2}{*}{20.704} \\
\hline Normotensive & $583(70.9 \%)$ & $69(8.4 \%)$ & $170(20.7 \%)$ & \\
\hline
\end{tabular}

Values in bold are statistically significant

Significant if $\chi^{2}>5.991$ 
significant differences were found between the two groups regarding attendance to the swimming pool.

When asked about the reasons for the non-participation in SE programs, the hypertensives place special emphasis on the feeling that the exercise is not adequate for their health (Table 2). It is important to point out that hypertensives report a lower preference for autonomous exercise, which may indicate that they would be more open to SE when well explained. The lack of time and activity schedules are factors more valued by normotensive, revealing that hypertensives are in some way more prone to accommodate exercise in their daily routine.

\section{PA information sources}

Considering that both hypertensives and normotensives embrace self-selected physical activity over SE, it is important to assess the information sources used by hypertensive and normotensive to evaluate the suitability and benefits of PA programs (Table 3).

The results from the comparison of means for independent samples reported in Table 3 show that there are differences in the information sources between hypertensives and normotensives in almost all categories. Doctors are the most valued information source for hypertensives, while sport professionals are preferred by normotensives. Both groups agree on the importance of friends and family as this category is placed second by them.

\section{Intention to participate in different types of pre-defined programs}

Aware of the generally low level of participation in existing PA programs, seven hypothetical scenarios were

Table 2 Causes of non-participation physical activities programs

\begin{tabular}{|c|c|c|c|c|c|c|}
\hline & \multicolumn{2}{|c|}{ Hypertensive } & \multicolumn{2}{|l|}{ Normotensive } & \multirow[t]{2}{*}{ Chi-square } & \multirow{2}{*}{$\begin{array}{l}\text { Asymptotic } \\
\text { significance }\end{array}$} \\
\hline & Yes & No & Yes & No & & \\
\hline The activities are not interesting & $43(53.1 \%)$ & $38(46.9 \%)$ & $143(33.5 \%)$ & $284(66.5 \%)$ & 11.266 & 0.001* \\
\hline Price & $46(37.4 \%)$ & $77(62.6 \%)$ & $284(46.0 \%)$ & $333(54.0 \%)$ & 3.092 & $0.079 * *$ \\
\hline Exercise is not adequate to my health & $34(37.4 \%)$ & $57(62.6 \%)$ & $106(21.5 \%)$ & $388(78.5 \%)$ & 10.679 & $0.001 *$ \\
\hline Distance & $38(39.6 \%)$ & $58(60.4 \%)$ & $193(39.0 \%)$ & $302(61 \%)$ & 0.012 & 0.913 \\
\hline Lack of time & $54(54.0 \%)$ & $46(46.0 \%)$ & $333(68.9 \%)$ & $150(31.1 \%)$ & 8.291 & $0.004 *$ \\
\hline Type of participants & $36(42.4 \%)$ & $49(57.6 \%)$ & $122(25.6 \%)$ & $354(74.4 \%)$ & 9.969 & $0.002 *$ \\
\hline Participation could be dangerous to my health & $31(31.3 \%)$ & $68(68.7 \%)$ & $89(17.1 \%)$ & $431(82.9 \%)$ & 10.727 & 0.001* \\
\hline Schedule & $47(49.5 \%)$ & $48(50.5 \%)$ & $278(60.2 \%)$ & $184(39.8 \%)$ & 3.712 & $0.054 * *$ \\
\hline Laziness/Lethargy & $44(45.4 \%)$ & $53(54.6 \%)$ & $175(36.7 \%)$ & $302(63.3 \%)$ & 2.570 & 0.109 \\
\hline Participation brings few benefits & $20(21.5 \%)$ & $73(78.5 \%)$ & $99(20.8 \%)$ & $378(79.2 \%)$ & 0.027 & 0.871 \\
\hline Lack of transportation & $30(28.0 \%)$ & $77(72.0 \%)$ & $115(23.4 \%)$ & $376(76.6 \%)$ & 1.019 & 0.313 \\
\hline Teacher training methodology & $32(36.4 \%)$ & $56(63.6 \%)$ & $165(35.3 \%)$ & $302(64.7 \%)$ & 0.034 & 0.853 \\
\hline I prefer doing self-select exercise & $32(33.7 \%)$ & $63(66.3 \%)$ & $192(43.7 \%)$ & $247(56.3 \%)$ & 3.240 & $0.072 * *$ \\
\hline
\end{tabular}

Bold values are significant

$* p<0.01$

$* * p<0.05$

Table 3 Information sources about PA

\begin{tabular}{lclllrrr}
\hline & Levene's $F$ & Levene's $p$ value & $\begin{array}{l}\text { Mean (SD) } \\
\text { hypertensive }\end{array}$ & $\begin{array}{l}\text { Mean (SD) } \\
\text { normotensive }\end{array}$ & $\begin{array}{l}t \text { test value } \\
\text { freedom }\end{array}$ & $\begin{array}{l}\text { Degrees of } \\
\text { f value }\end{array}$ \\
\hline By my doctor & 1.446 & 0.229 & $3.23(1.53)$ & $2.60(1.44)$ & 4.617 & 962 \\
By friends/family & 4.540 & 0.033 & $2.71(1.24)$ & $3.06(1.19)$ & -3.125 & 960 & $\mathbf{0 . 0 0 0 *}$ \\
By the Internet sites & 33.906 & 0.000 & $1.86(1.13)$ & $2.57(1.38)$ & -6.689 & 956 & $\mathbf{0 . 0 0 1 *}$ \\
By the Internet/social media & 15.136 & 0.000 & $1.71(1.09)$ & $2.22(1.27)$ & -4.950 & 957 & $\mathbf{0 . 0 0 0 *}$ \\
By a sports professional & 0.884 & 0.347 & $2.50(1.35)$ & $3.21(1.44)$ & -5.742 & 959 & $\mathbf{0 . 0 0 0 *}$ \\
By newspaper/magazines & 0.696 & 0.404 & $2.33(1.25)$ & $2.46(1.28)$ & -1.174 & 959 & 0.242 \\
\hline
\end{tabular}

Values in bold are statistically significant

*Statistically significant at the 0.05 level 
created exposing different conditions (indoor/outdoor, alone/with friends, paid/free, family participation, organized by social media online) to assess if this condition would affect the willingness to participate in PA programs. The results are reported in Table 4.

Hypertensives value exercising with the family, as well as outdoor activities. Normotensives display the same preference than hypertensives but consider also attractive the PA performed with friends. Both groups show low intention to participate in PA programs that are organized using social media. The cost does not seem to be a crucial factor for participation in SE programs.

Table 4 Intention to participate in physical activity programs

\begin{tabular}{|c|c|c|c|c|c|c|}
\hline & \multicolumn{2}{|c|}{ Hypertensive } & \multicolumn{2}{|l|}{ Normotensive } & \multirow[t]{2}{*}{ Chi-square } & \multirow{2}{*}{$\begin{array}{l}\text { Asymptotic } \\
\text { significance }\end{array}$} \\
\hline & Yes & No & Yes & No & & \\
\hline $\begin{array}{l}\text { Participate in a physical activity program that is organized } \\
\text { through online social media, at no cost to the user }\end{array}$ & $28(25.0 \%)$ & $84(75.0 \%)$ & $219(35.3 \%)$ & $402(64.7 \%)$ & 4.476 & $0.034 *$ \\
\hline $\begin{array}{l}\text { Participate in a physical activity program that is organized by } \\
\text { the Health Center and has free entry }\end{array}$ & $65(47.1 \%)$ & $73(52.9 \%)$ & $358(44.3 \%)$ & $450(55.7 \%)$ & 0.372 & 0.542 \\
\hline $\begin{array}{l}\text { I would participate in a physical activity program if I had a } \\
\text { personal trainer coming to my house }\end{array}$ & $47(43.9 \%)$ & $60(56.1 \%)$ & $287(46.7 \%)$ & $327(53.3 \%)$ & 0.291 & 0.590 \\
\hline $\begin{array}{l}\text { I would participate in a physical activity program that was } \\
\text { organized in the gardens/parks of my locality and had free } \\
\text { entrance }\end{array}$ & $65(63.1 \%)$ & $38(36.9 \%)$ & $432(70.8 \%)$ & $178(29.2 \%)$ & 2.482 & 0.115 \\
\hline $\begin{array}{l}\text { Participate in a physical activity program that allowed the } \\
\text { whole family to participate and had free entry }\end{array}$ & $68(64.8 \%)$ & $37(35.2 \%)$ & $458(74.6 \%)$ & $156(25.4 \%)$ & 4.413 & $0.036 *$ \\
\hline Participate in a physical activity program since it was outdoors & $64(62.1 \%)$ & $39(37.9 \%)$ & $439(73.3 \%)$ & $160(26.7 \%)$ & 5.382 & $0.020 *$ \\
\hline $\begin{array}{l}\text { I would participate in a physical activity program as long as it } \\
\text { was with my friends }\end{array}$ & $60(58.8 \%)$ & $42(41.2 \%)$ & $481(77.7 \%)$ & $138(22.3 \%)$ & 16.668 & $0.000 *$ \\
\hline
\end{tabular}

Values in bold are statistically significant

*Statistically significant at the 0.05 level

Table 5 Importance of the structure for the practice of physical activity

\begin{tabular}{|c|c|c|c|c|c|c|c|}
\hline & Levene's $F$ & Levene's $p$ value & $\begin{array}{l}\text { Mean (SD) } \\
\text { hyperten- } \\
\text { sive }\end{array}$ & $\begin{array}{l}\text { Mean (SD) } \\
\text { normoten- } \\
\text { sive }\end{array}$ & $t$ & $d f$ & $p$ value \\
\hline $\begin{array}{l}\text { Have specialists who know how to deal with my needs } \\
\text { (pathologies) }\end{array}$ & 9.651 & $0.002 *$ & $3.95(1.28)$ & $4.07(1.02)$ & -1.075 & 174.775 & 0.284 \\
\hline $\begin{array}{l}\text { Structure conditions (hygiene, furniture, equipment } \\
\text { type...) }\end{array}$ & 15.626 & $0.000 *$ & $3.9(1.22)$ & $4.16(0.91)$ & -2.385 & 17.511 & $0.018^{*}$ \\
\hline Localization & 2.183 & $0.000 *$ & $3.62(1.33)$ & $3.86(1.06)$ & -2.102 & 176.540 & $0.037 *$ \\
\hline Price & 31.129 & $0.000 *$ & $3.61(1.41)$ & $3.90(1.1)$ & -2.374 & 175.210 & $0.019 *$ \\
\hline Have good equipment & 26.095 & $0.000 *$ & $3.77(1.21)$ & $4.11(0.91)$ & -3.128 & 169.609 & $0.002 *$ \\
\hline $\begin{array}{l}\text { Have evaluation parameters (measure heart rate and } \\
\text { blood pressure) }\end{array}$ & 3.020 & 0.083 & $3.57(1.24)$ & $3.58(1.12)$ & -0.018 & 958 & 0.986 \\
\hline Have doctor/nurse & 4.375 & $0.037^{*}$ & $3.57(1.28)$ & $3.33(1.16)$ & 2.123 & 186.170 & $\mathbf{0 . 0 3 5 *}$ \\
\hline The fitness instructor has a degree in sports science & 1.570 & 0.210 & $3.56(1.26)$ & $3.66(1.18)$ & -0.920 & 957 & 0.358 \\
\hline Type of innovative activities & 0.252 & 0.615 & $3.17(1.15)$ & $3.74(1.07)$ & -5.781 & 956 & $0.000^{*}$ \\
\hline $\begin{array}{l}\text { Have another type of services (restaurant/bar, hair- } \\
\text { dresser, dance classes, nutritional advice...) }\end{array}$ & 0.665 & 0.415 & $2.73(1.29)$ & $2.92(1.25)$ & -1.644 & 956 & 0.101 \\
\hline Meet other participants & 2.069 & 0.151 & $2.99(1.25)$ & $3.29(1.11)$ & -2.865 & 957 & $0.004 *$ \\
\hline
\end{tabular}

Values in bold are statistically significant

*Statistically significant at the 0.05 level 


\section{Importance of the characteristics of the structure that hosts the exercise program}

To motivate hypertensives for SE programs, it is important to evaluate the characteristics perceived as more important for hypertensive, and if these differ from those selected by normotensive (Table 5).

In general, facilities seem to be very important for the practice of physical activity. Hypertensives value the presence of specialists that can deal with the disease, whereas they care less about the availability of another type of services, the academic qualifications of the fitness instructor, innovative activities and meet with other participants. It also should be noticed that there is no difference between hypertensives and normotensives regarding the importance given to the presence of a doctor or a nurse.

\section{Discussion}

This investigation aimed to compare SE patterns among hypertensive and normotensive Portuguese adults. Considering the PA level, and even though no significant statistical differences were found between groups, hypertensive individuals seem to show a tendency to have a higher prevalence of sedentary lifestyle than normotensive individuals (31.3\% vs $20.4 \%$ ). These results are in line with the literature, which indicates the prevalence of sedentary behavior in the hypertensive population [25].

Nair et al. [26] report $68 \%$ of hypertensives as inactive (IPAQ low level), while the current results show a lower incidence of inactive lifestyle among hypertensives. Similar to the current results, Riegel et al. [27] report 36\% of inactive hypertensives. Since a sedentary lifestyle in this population can aggravate its clinical condition, it is important to take the action and implement measures to promote the practice of exercise among this population.

About $40 \%$ of hypertensive patients have a high level of physical activity, which is a positive result, and better than the results described in similar studies by Martins et al. [28] and Al-Zalabani et al. [25] who found that only $20 \%$ and $18 \%$ of hypertensives reported high PA level. Portuguese hypertensives present a higher level of active lifestyle adoption; however, most of the PA is done autonomously since hypertensives display low participation rates in SE. Table 1 shows that the rate of attendance of SE facilities by hypertensives is lower for all sports facilities with exception to the swimming pool. This is particularly dangerous as the autonomous exercise by hypertensive patients increases the risk of unpredictable side-effects. For instance, inadequate exercise can acutely and transiently increase the risk of sudden cardiac death and acute myocardial infarction [29], and heart of patients with hypertension and cardiac hypertrophy is more vulnerable to ischemia-reperfusion injury [30].

The analysis of the reasons why hypertensives do not participate in SE when compared to the normotensive population reveals different patterns of barriers to exercise. Normotensive people consider the lack of time, schedule, and price as limiting factors for participation. Conversely, hypertensives consider the main causes for non-participation the particular interest on the type of program, the type of participants they will meet, and most importantly, the suitability of exercise for them and the fear of exercise being hazardous to their health. This is a very interesting result as it suggests that when considering existing exercise programs, hypertensive have a perception that they are not suitable for their health condition which may be a reason for the hypertensives' low level of participation in SE programs. Furthermore, this result also reveals deficiencies in the communication between the structures that host the programs and hypertensives to show that they have professionals and methods for adapting PA exercises to the special characteristics and needs of each participant. Similar results were reported by Wienert et al. [31] that found that they have significantly higher levels of perceived vulnerability which can influence the intention to engage in an active lifestyle.

Other barriers that prevent hypertensives from engaging in SE are identified in the literature [18], such as that (i) SE is not reimbursed by health insurance and that (ii) traveling to an exercise center three times weekly for SE is burdensome, especially for patients with impaired mobility. The consequence is that even when SE is offered without costs in a research program many subjects decline participation. Focusing elders with hypertension [32], the lower self-confidence and the lack of adequate societal and familial supports to maintain the recommended PA levels were identified as main barriers. Nair et al. [26] even consider the hypothesis of hypertensives develop a "Kinesiophobia", this is, a fear that exercise may be harmful to their health. The current study indicates that the causes for the non-participation in supervised exercises are very different for hypertensive and normotensive individuals and that hypertensives consider a larger set of barriers to justify their reluctance to exercise, being the major on the overestimation of the risks for their health condition.

The source of information has a crucial role in providing hypertensives with critical and accurate information regarding the benefits of SE and the risks associated with autonomous PA. The sources of information used by the two groups are quite different. Hypertensive individuals seek information from physicians, while normotensive individuals tend to rely on sports professionals, and on friends/relatives. It is interesting and puzzling to note that hypertensives do not trust sports specialists to get counseling in what they are specialists. This finding calls for additional investigations 
on the credibility of sports professionals among this population, namely on what can be done to increase the perception and confidence on them. Due to the absence of credibility by sports professionals to prescribe PA programs to hypertensives, it would be crucial to put doctors to work closely with sports professionals to effectively promote PA among hypertensives [33]. Current findings highlight that (1) physicians are key players in promoting supervised exercise in the hypertensive population, and (2) that the promotion of PA through the Internet/online social networks is very ineffective since hypertensive individuals seek little information on PA in these media.

Regarding the intention to participate in different types of pre-defined programs, it can be concluded that hypertensive individuals show a lower intention to participate than normotensive. This result shows some similarity with the literature [31] by exposing that hypertensives show no intention of changing inactive behavior habits, neither on participating in PA programs either independent or supervised. Normotensives show a greater intention to participate in outdoor programs with family and friends. The support of family, friends backed by the healthcare professionals could greatly improve the participation is PA programs by hypertensive patients. These findings highlight the importance of designing exercise programs and communication targeted to hypertensive patients jointly with the family and healthcare professionals.

Likewise, the characteristics of the structure that hosts the exercise program should be addressed in spite of the fact of hypertensives reporting having similar requirements to normotensives. However, since the participation rate among hypertensives is low, it can be questioned if the responses are due to lack of knowledge about the conditions of these structures. Further investigation regarding this condition is needed to clarify the importance of the facilities and equipment on the motivation to adhere to PA programs. An intriguing result is that hypertensive patients do not value the presence of a sports specialist with professional competence to adjust the exercise to their pathology.

\section{Conclusion}

The findings of the current study point out the existence of differences between hypertensive and normotensive individuals regarding SE. These differences should be taken into account when designing an operative strategy to promote SE among hypertensives. Moreover, since both hypertensive and normotensive reported a regular PA level (about two-thirds with a moderate or high level) but very low participation in SE programs, it seems important to implement programs devoted to increasing PA as a way of preventing future health issues. Hypertensives perceive that structured exercise is not adequate for their health, which is a major barrier to participate in organized, and supervised programs. This conclusion implies a lack of information on the benefits of SE and its advantages versus autonomous physical activities. It also reveals a gap between the service providers (gym/health club/sport facilities managers) and potential clients (hypertensives), which seem incapable to make them aware of the risks associated with PA and the potential benefits and security associated with SE. This is an issue were a collaboration between sports professionals and doctors seems decisive to the success of SE programs as hypertensives rely mostly on the information provided by doctors, and people they trust.

In general, the attitude toward PA is only slightly different between hypertensives and normotensives; therefore, a customized communication approach is only necessary to deal with specific fears and uncertainties of hypertensive namely to help them face the worries about potential side-effects. Yet, both groups need to know the benefits of SE which is safer for individuals with hypertension. Sports and healthcare professional, market agents and policymakers must be aware of this different behavior patterns when designing and marketing SE programs among the target population to increase adherence rates.

Finally, a note of caution must be acknowledged regarding the analysis of the intention to participate in different types of pre-defined programs since some questions were formulated with two conditions that imposed difficulties to the analyze as answers can be influenced either by the first or the second condition. Therefore, the findings associated with these questions should be interpreted carefully.

Funding There is no funding associated with this research.

\section{Compliance with ethical standards}

Ethics approval (IRB) The study protocol conformed to the Declaration of Helsinki and was conducted with the Scientific Committee of $\mathrm{Ph} . \mathrm{D}$. Sports Science from the University of Beira Interior approval (no number assigned).

Informed consent All respondents were unambiguously informed about the study's objectives, that participation was voluntary, and anonymity was assured. Explicit verbal agreement regarding participation was obtained from all participants before answering the questionnaire.

\section{References}

1. Bloch MJ (2016) Worldwide prevalence of hypertension exceeds 1. 3 billion. J Am Soc Hypertens 10:753-754. https://doi. org/10.1016/j.jash.2016.08.006 
2. Chockalingam A, Campbell NR, Fodor JG (2006) Worldwide epidemic of hypertension. Can J Cardiol. 22(7):553-555

3. Pedersen BK, Saltin B (2015) Exercise as medicine-evidence for prescribing exercise as therapy in 26 different chronic diseases. Scand J Med Sci Sport 25:1-72. https://doi.org/10.1111/ sms. 12581

4. Frieden TR, Jaffe MG (2018) Saving 100 million lives by improving global treatment of hypertension and reducing cardiovascular disease risk factors. J Clin Hypertens 20:208-211. https://doi. org/10.1111/jch.13195

5. Williams B, Mancia G, Spiering W et al (2018) 2018 ESC/ESH Guidelines for the management of arterial hypertension. J Hypertens 36:1953-2041. https://doi.org/10.1097/HJH.0000000000 001940

6. Herrod PJJ, Doleman B, Blackwell JEM et al (2018) Exercise and other nonpharmacological strategies to reduce blood pressure in older adults: a systematic review and meta-analysis. J Am Soc Hypertens 12:248-267. https://doi.org/10.1016/j.jash.2018.01.008

7. Cavalcante PA, Rica R, Evangelista A et al (2015) Effects of exercise intensity on postexercise hypotension after resistance training session in overweight hypertensive patients. Clin Interv Aging 10:1487. https://doi.org/10.2147/CIA.S79625

8. James PA, Oparil S, Carter BL et al (2014) 2014 evidence-based guideline for the management of high blood pressure in adults. JAMA 311:507. https://doi.org/10.1001/jama.2013.284427

9. Romero Blanco C, Villalvilla Soria DJ, Cabanillas Cruz E et al (2015) Cumplimiento de las recomendaciones de actividad física para la salud en adultos hipertensos. Nutr Hosp 31:415-420. https ://doi.org/10.3305/nh.2015.31.1.7423

10. Cornelissen VA, Fagard RH (2005) Effects of endurance training on blood pressure, blood pressure-regulating mechanisms, and cardiovascular risk factors. Hypertension 46:667-675. https://doi. org/10.1161/01.HYP.0000184225.05629.51

11. Cornelissen VA, Smart NA (2013) Exercise training for blood pressure: a systematic review and meta-analysis. J Am Heart Assoc 2:1-9. https://doi.org/10.1161/JAHA.112.004473

12. Schultz MG, La Gerche A, Sharman JE (2017) Blood pressure response to exercise and cardiovascular disease. Curr Hypertens Rep 19:1-7. https://doi.org/10.1007/s11906-017-0787-1

13. Gliemann L, Buess R, Nyberg M et al (2015) Capillary growth, ultrastructure remodelling and exercise training in skeletal muscle of essential hypertensive patients. Acta Physiol 214:210-220. https://doi.org/10.1111/apha.12501

14. Nyberg M, Gliemann L, Hellsten Y (2015) Vascular function in health, hypertension, and diabetes: effect of physical activity on skeletal muscle microcirculation. Scand J Med Sci Sport 25:60-73

15. Eckel RH, Jakicic JM, Ard JD et al (2014) 2013 AHA/ACC guideline on lifestyle management to reduce cardiovascular risk: a report of the American college of cardiology/American heart association task force on practice guidelines. J Am Coll Cardiol 63:2960-2984. https://doi.org/10.1016/j.jacc.2013.11.003

16. Piepoli MF, Hoes AW, Agewall S et al (2016) 2016 European Guidelines on cardiovascular disease prevention in clinical practice. Atherosclerosis 252:207-274. https://doi.org/10.1016/j.ather osclerosis.2016.05.037

17. Dopheide JF, Rubrech J, Trumpp A et al (2017) Supervised exercise training in peripheral arterial disease increases vascular shear stress and profunda femoral artery diameter. Eur J Prev Cardiol 24:178-191. https://doi.org/10.1177/2047487316665231

18. McDermott MM, Polonsky TS (2016) Home-based exercisea therapeutic option for peripheral artery disease. Circulation 134:1127-1129. https://doi.org/10.1161/CIRCULATIO NAHA.116.023691
19. Motlagh Z, Hidarnia A, Kaveh MH, Kojuri J (2017) Effect of theory-based training intervention on physical activity and blood pressure in hypertensive patients: a randomized control trial. Iran Red Crescent Med J. https://doi.org/10.5812/ircmj.55610

20. Arboix A, Roig H, Rossich R et al (2004) Differences between hypertensive and non-hypertensive ischemic stroke. Eur J Neurol 11:687-692. https://doi.org/10.1111/j.1468-1331.2004.00910.x

21. Craig CL, Marshall AL, Sjöström M et al (2003) International physical activity questionnaire: 12-country reliability and validity. Med Sci Sports Exerc 35:1381-1395. https://doi.org/10.1249/01. MSS.0000078924.61453.FB

22. Hagströmer M, Oja P, Sjöström M (2006) The International Physical Activity Questionnaire (IPAQ): a study of concurrent and construct validity. Public Health Nutr 9:755-762. https://doi. org/10.1079/PHN2005898

23. Thomas N, Alder E, Leese GP (2004) Barriers to physical activity in patients with diabetes. Postgrad Med J 80:287-291. https://doi. org/10.1136/pgmj.2003.010553

24. Pinheiro P, Esteves D, Brás R (2012) Effect of internet and social networks on knowledge regarding physical activity. Int J Manag Sci Technol Inf 4:29-41

25. Al-Zalabani A, Saeed A, Al-Hamdan N (2012) Comparative study of physical activity of hypertensives and normotensives: a crosssectional study of adults in Saudi Arabia. J Fam Community Med 19:162. https://doi.org/10.4103/2230-8229.102315

26. Nair SP, Ganu SS, Farhnin I (2017) Impact of kinesiophobia on physical activity in patients with arterial hypertension. Int $\mathrm{J}$ Health Sci Res 7:170-175

27. Riegel GR, Martins GB, Schmidt AG et al (2019) Self-reported adherence to physical activity recommendations compared to the IPAQ interview in patients with hypertension. Patient Prefer Adherence 13:209-214. https://doi.org/10.2147/ppa.s185519

28. Martins LCG, Guedes NG, Teixeira IX et al (2011) Physical activity level in people with high blood pressure. Rev Lat Am Enfermagem 17:462-467. https://doi.org/10.1590/s0104-1169200900 0400005

29. Thompson PD, Franklin BA, Balady GJ et al (2007) Exercise and acute cardiovascular events. Circulation 115:2358-2368. https:// doi.org/10.1161/CIRCULATIONAHA.107.181485

30. Pagliaro P, Penna C (2017) Hypertension, hypertrophy, and reperfusion injury. J Cardiovasc Med 18:131-135. https://doi. org/10.2459/JCM.0000000000000435

31. Wienert J, Kuhlmann T, Fink S et al (2017) Motivational and volitional correlates of physical activity in participants reporting no, past, and current hypertension: findings from a crosssectional observation study. Int J Behav Med 24:908-914. https ://doi.org/10.1007/s12529-017-9649-0

32. Gong J, Xu Y, Chen X et al (2018) Persistent effect at 30-month post intervention of a community-based randomized trial of $\mathrm{KM} 2 \mathrm{H} 2$ in reducing stroke and heart attack among senior hypertensive patients. Int J Behav Nutr Phys Act 15:1-12. https://doi. org/10.1186/s12966-017-0635-3

33. Maiorana AJ, Williams AD, Askew CD et al (2018) Exercise professionals with advanced clinical training should be afforded greater responsibility in pre-participation exercise screening: a new collaborative model between exercise professionals and physicians. Sport Med 48:1293-1302. https://doi.org/10.1007/s4027 9-018-0888-2

Publisher's Note Springer Nature remains neutral with regard to jurisdictional claims in published maps and institutional affiliations. 